\title{
Relationship between Psychological Correlates and Empathy in Medical Students: A Cross-Sectional Study
}

\author{
Won Woo Suh1, Sung Hyun Cho', Ji Yeon Yoo', Hyun Soo Kim¹, Hoo Rim Song1, \\ Woo Jung Kim ${ }^{1}$, Sang Min Lee ${ }^{2}$, and Minha Hong ${ }^{1 凶}$ \\ ${ }^{1}$ Department of Psychiatry, Hanyang University College of Medicine, Myongji Hospital, Goyang, Republic of Korea \\ ${ }^{2}$ Department of Psychiatry, Kyung Hee University College of Medicine, Kyung Hee University Hospital, Seoul, Republic of Korea
}

Objective Empathy is important in the education of medical students. Many psychosocial variables are related to empathy. The aim of the study was to investigate the relationship between empathy and psychosocial factors such as burnout, personality, self-esteem, and resilience. Methods The participants completed a set of self-reporting questionnaires, including questions related to socio-demographic characteristics, the Korean edition of the Jefferson Scale of Empathy, student version (JSE-S-K), Maslach Burnout Inventory General Survey (MBIGS), NEO Five-Factor Inventory (NEO-FFI), Rosenberg Self-esteem Scale (R-SES), and Connor-Davidson Resilience Scale (CD-RISC). Partial correlation and regression analyses were performed.

Results In male students, there were positive correlations between JSE-S-K and R-SES ( $\mathrm{r}=0.229, \mathrm{p}=0.002)$; conscientiousness of the NEO-FFI ( $r=0.153, p=0.037)$ and negative correlations, specifically between JSE-S-K and depersonalization of MBI $(r=-0.206$, $p=0.005)$. In female students, there was positive correlations between JSE-S-K and personal accomplishment of MBI $(r=0.384, p=0.004)$. In the multiple regression model, the JSE-S-K was affected by conscientiousness of the NEO-FFI (adjusted $\mathrm{R}^{2}=0.245$, $\beta=0.201$, $\mathrm{p}=0.001$ ); depersonalization, personal accomplishment of the MBI-GS $(\beta=-0.188, \mathrm{p}=0.001, \beta=0.143, \mathrm{p}=0.017)$; R-SES $(\beta=0.176, \mathrm{p}=0.004) ; \operatorname{sex}(\beta=0.117, \mathrm{p}=0.029)$. Conclusion The present findings suggested that conscientiousness, depersonalization, personal accomplishment, self-esteem and sex have an influence on empathy. Therefore, these must be considered in medical education and can be helpful to nurture more empathetic doctors.

Psychiatry Investig 2019;16(10):766-772

Key Words Medical student, Empathy, Self-esteem, Burnout, Conscientiousness.

\section{INTRODUCTION}

It is well known that empathy defined as understanding the patient's thought and feeling ${ }^{1}$ has an impact on interpersonal relationship. ${ }^{2}$ People can be empathetic by putting himself or herself at the other's stance. ${ }^{1}$ Hence, empathy has long been recognized as important, not only for better communication in

Received: May 17, 2019 Revised: July 15, 2019

Accepted: August 31, 2019

$\triangle$ Correspondence: Minha Hong, $\mathrm{MD}, \mathrm{PhD}$

Department of Psychiatry, Hanyang University College of Medicine, Myongji Hospital, 55 Hwasu-ro 14 Beon-gil, Deokyang-gu, Goyang 10475, Republic of Korea

Tel: +82-31-810-6230, Fax: +82-31-969-0500, E-mail: npmhhong@gmail.com

$\bowtie$ Correspondence: Sang Min Lee, MD, PhD

Department of Psychiatry, Kyung Hee University College of Medicine, Kyung Hee University Hospital, 23 Kyungheedae-ro, Dongdaemun-gu, Seoul 02447, Republic of Korea

Tel: +82-2-958-8543, Fax: +82-2-957-1997, E-mail: mini7744@hanmail.net

(c) This is an Open Access article distributed under the terms of the Creative Commons Attribution Non-Commercial License (https://creativecommons.org/licenses/by$\mathrm{nc} / 4.0$ ) which permits unrestricted non-commercial use, distribution, and reproduction in any medium, provided the original work is properly cited. the patient-doctor relationship but also for improved patient compliance, and better prognosis and treatment outcomes. ${ }^{3-6}$

Bringing up empathetic doctors and lowering the increasing stress and burnout among medical students are global priorities.

To develop more empathetic doctors, the Association of American Medical Colleges added empathy as a learning objective in medical education. ${ }^{4}$ Domestic medical colleges in Korea also made revisions to the medical curriculum to strengthen the capacity for empathy. ${ }^{5}$

From behavioral and social sciences perspectives, the ability to modify one's empathy is controversial: empathy as trait is highly stable and difficult to change but empathy as state is easy to change. ${ }^{6}$ Hojat $^{7}$ suggested that empathy resembles the concept of attachment and has its basis in evolutionary, genetic, developmental, experiential, situational, and educational grounds.

In addition, deficits in empathy may be improved by therapeutic or interventional approaches. ${ }^{7}$ Although there is a lack 
of consistent positive results in improving empathy through medical education, current evidence supports the need for targeted programs and appropriate experiences for medical students. This is because not everyone develops the capacity for empathy by default.

The Jefferson Scale of Empathy (JSE) was developed to measure empathy among medical students and physicians. The validity and reliability of JSE are well established. It has been translated into various languages and is widely used in many countries, particularly in the field of health and patient care. ${ }^{8-10}$

Up to $60 \%$ of physicians experience burnout during their career. Emotionally exhausted physicians are generally less empathetic and may become depersonalized when managing patients. ${ }^{11}$ The features of burnout such as depersonalization, emotional exhaustion, and decline in personal accomplishment are prevalent not only among physicians but also frequently affect medical students. ${ }^{12}$ Previous studies investigating the association between burnout and empathy in physicians and medical students have reported that emotional exhaustion and depersonalization are inversely correlated with empathy. ${ }^{11,13,14}$

Resilience is also one of the psychosocial factors assumed to be related to empathy. Resilience is the ability to deal with stress and to recover from the adversity. ${ }^{15}$ A previous study delineated how resilience, burnout, and empathy in physicians are related. ${ }^{16}$ The researchers concluded that only burnout is related to resilience. ${ }^{16}$ However, they did point out that additional investigations to further explore this relationship is warranted. ${ }^{16}$

It is also well known that personality, a construction of behavioral tendencies and characteristics, ${ }^{17}$ has an impact on the empathy of medical students..$^{10,17-19}$ The five factor model, characterized by five personality dimensions (neuroticism, extraversion, conscientiousness, agreeableness, openness to experience), is often applied to evaluate the personality of medical students in relation to empathy. ${ }^{17-19}$ It has been shown that medical students who are more open to experience and agreeable tend to be more empathetic because they can build better doctor-patient relationships and handle the unexpected. ${ }^{18,19}$ Self-esteem is defined as the value that individuals places on themselves. ${ }^{20}$ There have been many studies that tried to figure out the relation between empathy and self-esteem..$^{20-22}$ It is already known that self-esteem may be affected by empathy. ${ }^{23-25}$ However, the impact of self-esteem on empathy, especially among medical students, has remained inconclusive.

A number of studies in the literature have investigated the factors relating to empathy among medical students or physicians in Korea. ${ }^{10,26-28}$ Relationship between empathy and personality of medical students were figured out using the Jefferson Scale of Empathy, Student-version, Korean edition (JSE$\mathrm{S}-\mathrm{K})$ and Temperament and Character Inventory (TCI). ${ }^{10}$
According to Lee et al., ${ }^{10}$ the empathy was related to Reward Dependence, Cooperativeness subscales of TCI. ${ }^{10}$ Another study conducted on training residents with various specialties, reported that emotional exhaustion and depersonalization subscales of Maslach Burnout Inventory were negatively related to empathy. To our knowledge, our study is the first to investigate the correlates between empathy and the multiple psychological variables such as self-esteem, resilience in a single medical student group in Korea. In particular, the aim of this study was to investigate the relationships among empathy, burnout, personality, resilience, and self-esteem within one medical students group. Our hypothesis is that empathy is inversely correlated with burnout and neuroticism; and positively correlated with resilience, self-esteem, and four of the domains in the five-factor model (extraversion, conscientiousness, agreeableness, and openness to experience).

\section{METHODS}

\section{Participants}

In this cross-sectional study, 285 students from the Seonam University in South Korea were invited to participate. The medical college of Seonam University has the 6-year curriculum with students from high school graduates. The 6-year curriculum is divided into 2-year premedical, basic, and clinical courses.

A survey was completed in the middle of the academic year (from November to December 2016). The students received the survey via postal mail, or directly from one of the researchers. In total, 271 students (197 men, 74 women; response rate: 95\%) responded. Participation in this study was voluntarily and students were not compensated.

\section{Ethics approval and consent to participate}

This study was approved by the Institutional Review Board of Myongji Hospital (approval No. MJH-16-115). Informed consent was submitted by all subjects when they were enrolled.

\section{Measurement tools}

\section{Socio-demographic characteristics}

The questionnaire included items assessing sex, age and year level.

\section{Korean edition of the Jefferson Scale of Empathy- student version (JSE-S-K)}

The Jefferson Scale of Empathy was developed by Hojat et al. ${ }^{8}$ to assess the empathic capacity of health professions. The JSE-S was translated into Korean in 2010 and was reported to have a Cronbach's alpha of $0.84 .^{29}$ The JSE-S-K is a self-report- 
ing questionnaire consisting of 20 items, with a 7-point Likert scale from 1 (strongly disagree) to 7 (strongly agree). Among the 20 items, 10 are reverse items, with responses from 1 (strongly agree) to 7 (strongly disagree). The total score was obtained by summing all items (maximum score $=140$ ). A higher total score indicates higher degree of empathy.

\section{Maslach Burnout Inventory-general survey version (MBI-GS)}

The $\mathrm{MBI}^{30}$ is a widely used self-reporting scale to assess burnout states related to occupational stress. There are two versions of MBI: the general survey and human services survey versions. We used the general survey version translated by Kang and Kim. ${ }^{31}$ The MBI consists of 22 items with three subscales: emotional exhaustion (EE, 9 items), depersonalization (DP, 5 items), and personal accomplishment (PA, 8 items). Responses are provided on a 7-point Likert scale from 1 to 7 . A higher burnout state is associated with higher EE and DP, and lower PA scores. ${ }^{13}$

\section{Conner-Davidson Resilience Scale (CD-RISC)}

The CD-RISC is a 25 -item, self-reporting scale to estimate psychological resilience and coping ability. ${ }^{32}$ Each item is scored on a 5-point scale (0-4). A higher score indicates better psychological resilience. In factor analysis, the CD-RISC is divided into five sub-factors: hardness, persistence, optimism, support, and spirituality. High reliability and validity of the CDRISC have been established in various groups. The Korean version of the CD-RISC developed in 2010 was applied to our study. Validity (Cronbach's alpha $>0.9$ ) and test- retest reliability (Pearson $r=0.7$ ) were confirmed in samples comprising of university students, nurses, and firefighters. ${ }^{33}$

\section{Rosenberg Self-Esteem Scale (RSES)}

The RSES assesses the attitudes toward the self (i.e., sense of self-worth and self-acceptance). ${ }^{34}$ This is a 10 -item, self-reporting scale. Items are rated on a 4-point Likert scale ( $1=$ strongly disagree, $4=$ strongly agree). Item ratings are summed to yield a total score (ranges from 10 to 40). A higher score indicates higher self-esteem. In this study, we used the version translated and validated by Lee. ${ }^{35}$

\section{Neuroticism Extraversion Openness Five-Factor Inventory (NEO-FFI)}

The NEO-FFI is one of the self-reporting questionnaires based on the five-factor model of personality. ${ }^{36}$ The NEO-FFI is used to assess the five major dimensions of personality traits by means of a questionnaire comprising of 60 items, using a 5 -point Likert scale. The five dimensions are neuroticism $(\mathrm{N})$, extraversion (E), openness $(\mathrm{O})$, agreeableness $(\mathrm{A})$, and con- scientiousness (C). Neuroticism includes characteristics such as anxiety, anger, hostility, and depression. Extraversion comprises dimensions such as warmth, activity, positive emotions, and excitement-seeking. Conscientiousness refers to dimensions such as self-discipline, dutifulness, and competence. Agreeableness consists of trust, altruism, modesty, compliance, and tender-mindedness. Openness to experience includes imagination, ideas, values, feelings, aesthetics, and actions. ${ }^{37} \mathrm{We}$ used the translated version of the NEO-FFI in this study (Cronbach's alpha $0.718^{-0.801) .{ }^{38}}$

\section{Data analysis and statistics}

Descriptive statistics were computed for the socio-demographic variables and JSE-S-K scores. An independent samples T-test was performed to investigate differences in empathy depending on sex. One-way analysis of variance (ANOVA) was applied to find out difference of empathy by grade. Pearson correlation analysis was applied to examine correlations between empathy and other factors, such as resilience and personality. Following the criteria proposed by Cohen, a relationship between two factors is considered a significant correlation when the calculated value is higher than the median value ( $\mathrm{r}=0.300, \mathrm{r}=$ Pearson correlation coefficients) in this study. ${ }^{39}$ To investigate the correlation between empathy and other factors with adjusting confounding factors, partial correlation analysis was used. As sex could be hypothesized as a confounding factor, the relationships between sex and burnout, resilience, self-esteem and personality were figured out with spearman's rho correlation analysis. Also when partial correlation analysis was applied, it was done for male and female students respectively to minimize sex effects. With partial correlation analysis, statistically significant variables were chosen for multiple regression analysis. Multiple regression analysis with stepwise method was performed to test the degree of effects of scales that were found to have significant correlations with empathy. First, it was applied for each sex and second, it was applied for whole students to identify which independent variable is more influential to empathy, sex or other psychological factors. $P$ value $<0.05$ was considered statistically significant in all analyses. All statistical analyses were performed using PASW. ${ }^{18}$

\section{RESULTS}

\section{Socio-demographic characteristics and empathy}

While there was no statistically significant difference in JSES-K scores according to grades (Table 1), the JSE-S-K mean score of female students (111.09 \pm 12.66$)$ was significantly higher than that of the male students $(107.29 \pm 14.37)(\mathrm{p}=0.046)$ (Table 2). 


\section{Correlation analysis}

To investigate the relationship among empathy and other psychological factors, Pearson correlation analysis was performed with the total scores of the JSE-S-K, each score of the three subscales in the MBI-GS, each score of the five subscales in the NEO-FFI, total scores of the R-SES and CD-RS. There were statistically significant correlations between empathy and all psychological factors (Table 3), and statistically significant correlations among other psychological variables were also found (Table 3).

With partial correlation analysis, self-esteem, conscientiousness and depersonalization of burnout were related to empathy statistically significantly in male students.

Only personal accomplishment of burnout was related to

Table 1. Empathy score by grade Unit: N (\%)

\begin{tabular}{lcrcc}
\hline Grade & Male & Female & Age $($ mean \pm SD $)$ & JSE-S-K \\
\hline 1st & $32(73)$ & $13(27)$ & $20.4 \pm 1.2$ & $107.93 \pm 14.7$ \\
2nd & $33(89)$ & $4(11)$ & $21.3 \pm 1.1$ & $105.65 \pm 15.7$ \\
3rd & $43(74)$ & $15(26)$ & $23.7 \pm 3.1$ & $111.14 \pm 13.3$ \\
4th & $28(65)$ & $15(35)$ & $23.5 \pm 2.0$ & $109.26 \pm 11.7$ \\
5th & $31(67)$ & $15(33)$ & $24.7 \pm 3.4$ & $110.78 \pm 13.0$ \\
6th & $30(71)$ & $12(29)$ & $26.2 \pm 3.0$ & $103.59 \pm 14.5$ \\
Total & $197(73)$ & $74(27)$ & 23.4 & $108.32 \pm 14.0$ \\
\hline
\end{tabular}

JSE-S-K: Jefferson Scale of Empathy, Student version, Korean edition

Table 2. Empathy score by gender, attachment type, and medical specialty of medical students

\begin{tabular}{lcccc}
\hline \multicolumn{1}{c}{ Sex } & JSE-S-K $($ mean \pm SD $)$ & T & p & N \\
\hline Male & $107.29 \pm 14.37$ & -2.01 & 0.046 & 197 \\
Female & $111.09 \pm 12.66$ & & & 74 \\
\hline
\end{tabular}

JSE-S-K: Jefferson Scale of Empathy, Student version, Korean edition empathy statistically significantly in female students (Table 4).

With spearman's rho correlation analysis, there were no significant correlations between sex and other independent variables.

\section{Regression analysis}

Multiple regression analysis was performed to investigate how much the scales which showed statistically significant correlations with empathy including self-esteem, depersonalization and personal accomplishment in the MBI, and conscientiousness in the NEO-FFI had effects on empathy. The anal-

Table 4. Partial correlation coefficients between burnout, personality, self-esteem, resilience, quality of life and empathy in students

\begin{tabular}{lcccccc}
\hline \multirow{2}{*}{ Instruments } & \multicolumn{3}{c}{ Male } & & \multicolumn{2}{c}{ Female } \\
\cline { 2 - 3 } \cline { 7 - 7 } MBI & Subscale & JSE-S-K & $\mathrm{p}$ & & JSE-S-K & $\mathrm{p}$ \\
\hline \multirow{2}{*}{ NEO-FFI } & $\mathrm{EE}$ & 0.096 & 0.190 & & -0.048 & 0.702 \\
& $\mathrm{PA}$ & 0.077 & 0.293 & & $0.348^{*}$ & 0.004 \\
& $\mathrm{DP}$ & $-0.206^{*}$ & 0.005 & & 0.060 & 0.636 \\
& $\mathrm{~N}$ & -0.039 & 0.592 & & 0.005 & 0.966 \\
& $\mathrm{E}$ & -0.099 & 0.177 & & -0.205 & 0.101 \\
& $\mathrm{O}$ & 0.094 & 0.201 & & -0.069 & 0.587 \\
& $\mathrm{~A}$ & 0.078 & 0.290 & & -0.015 & 0.903 \\
R-SES* & $\mathrm{C}$ & $0.153^{*}$ & 0.037 & & 0.199 & 0.113 \\
CD-RISC & & $0.229^{*}$ & 0.002 & & 0.021 & 0.866 \\
\hline
\end{tabular}

p-value: two tailed, ${ }^{*} \mathrm{p}<0.05$. JSE-S-K: Jefferson Scale of Empathy, Student version, Korean edition, MBI: Maslach Burnout Inventory, NEO-FFI: NEO Five-Factor Inventory, EE: emotional exhaustion, N: neuroticism, A: agreeableness, PA: personal accomplishment, E: extraversion, C: conscientiousness, DP: depersonalization, O: openness, R-SES: Rosenberg Self-Esteem Scale, CD-RISC: Conner-Davidson Resilience Scale

Table 3. Pearson's correlation coefficients among empathy and psychological factors in students

\begin{tabular}{lcccccccccccc}
\hline & JSE-S-K & R-SES & $\mathrm{N}$ & $\mathrm{E}$ & $\mathrm{O}$ & $\mathrm{A}$ & $\mathrm{C}$ & $\mathrm{EE}$ & $\mathrm{PA}$ & $\mathrm{DP}$ & $\mathrm{CD}-\mathrm{RS}$ \\
\hline JSE-S-K & 1 & $0.359^{*}$ & $-0.169^{\dagger}$ & $0.191^{\dagger}$ & $0.236^{*}$ & $0.238^{*}$ & $0.365^{*}$ & $0.191^{\dagger}$ & $0.318^{*}$ & $-0.323^{*}$ & $0.375^{*}$ \\
$\mathrm{R}-\mathrm{SES}{ }^{*}$ & $0.359^{*}$ & 1 & $-0.392^{*}$ & $0.468^{*}$ & $0.258^{*}$ & $0.279^{*}$ & $0.364^{*}$ & $-0.416^{*}$ & $0.362^{*}$ & $-0.336^{*}$ & $0.513^{*}$ \\
$\mathrm{~N}$ & $-0.169^{\dagger}$ & $-0.392^{*}$ & 1 & 0.096 & $0.255^{*}$ & $-0.150^{\dagger}$ & 0.003 & $0.564^{*}$ & $-0.235^{*}$ & $0.418^{*}$ & $-0.305^{*}$ \\
$\mathrm{E}$ & $0.191^{\dagger}$ & $0.468^{*}$ & $0.096^{*}$ & 1 & $0.538^{*}$ & $0.266^{*}$ & $0.457^{*}$ & $-0.187^{\dagger}$ & $0.491^{*}$ & -0.094 & $0.478^{*}$ \\
$\mathrm{O}$ & $0.236^{*}$ & $0.258^{*}$ & $0.255^{*}$ & $0.538^{*}$ & 1 & $0.140^{\dagger}$ & $0.436^{*}$ & 0.103 & $0.326^{*}$ & -0.030 & $0.423^{*}$ \\
$\mathrm{~A}$ & $0.238^{*}$ & $0.279^{*}$ & -0.159 & $0.266^{*}$ & $0.140^{\dagger}$ & 1 & $0.196^{\dagger}$ & $-0.262^{*}$ & $-0.299^{*}$ & $-0.330^{*}$ & $0.193^{\dagger}$ \\
$\mathrm{C}$ & $0.365^{*}$ & $0.364^{*}$ & 0.003 & $0.457^{*}$ & $0.436^{*}$ & $0.196^{\dagger}$ & 1 & -0.059 & $0.359^{*}$ & $-0.204^{*}$ & $0.526^{*}$ \\
$\mathrm{EE}$ & $0.191^{\dagger}$ & -0.416 & 0.564 & $-0.187^{\dagger}$ & $0.103^{*}$ & $-0.262^{*}$ & $-0.059^{*}$ & 1 & $-0.258^{*}$ & $0.579^{*}$ & $-0.304^{*}$ \\
$\mathrm{PA}$ & $0.318^{*}$ & $0.362^{*}$ & $-0.235^{*}$ & $0.491^{*}$ & $0.326^{*}$ & $-0.299^{*}$ & $0.359^{*}$ & $-0.258^{*}$ & 1 & $-0.250^{*}$ & $0.641^{*}$ \\
DP & $-0.323^{*}$ & $-0.336^{*}$ & $0.418^{*}$ & -0.094 & -0.030 & $-0.330^{*}$ & $-0.204^{*}$ & $0.579^{*}$ & $-0.250^{*}$ & 1 & $-0.348^{*}$ \\
$\mathrm{CD}-\mathrm{RS}$ & $0.375^{*}$ & $0.513^{*}$ & $-0.305^{*}$ & $0.478^{*}$ & $0.423^{*}$ & $0.193^{\dagger}$ & $0.526^{*}$ & $-0.304^{*}$ & $0.641^{*}$ & $0.348^{*}$ & 1 \\
\hline
\end{tabular}

p-value: two tailed, ${ }^{*} \mathrm{p}<0.0001,{ }^{\dagger} \mathrm{p}<0.05$. JSE-S-K: Jefferson Scale of Empathy, Student version, Korean edition, MBI: Maslach Burnout Inventory, NEO-FFI: NEO Five-Factor Inventory, EE: emotional exhaustion, N: neuroticism, A: agreeableness, PA: personal accomplishment, E: extraversion, C: conscientiousness, DP: depersonalization, O: openness, R-SES: Rosenberg Self-Esteem Scale, CD-RISC: Conner-Davidson Resilience Scale 
ysis was done for male and female students respectively (Table 5-1, 5-2).

With stepwise method, the analysis of variance found that the model was statistically significant for each sex $(\mathrm{F}=21.247$, $\mathrm{p}<0.0001 ; \mathrm{F}=16.462, \mathrm{p}<0.0001)$ and adjusted $\mathrm{R}$ square is 0.238 and 0.298 for male and female respectively. The multiple variance inflation factor (VIF) of all independent variables was below 10 in both sex, indicating that there was no correlation between the independent variables. Self-esteem $(\beta=0.248, \mathrm{p}=$ $0.001)$, conscientiousness $(\beta=0.214, p=0.002)$ in the NEO-FFI, depersonalization $(\beta=-0.221, p=0.001)$ in the MBI were significantly associated with empathy in male students (Table 5-1). In female students, Personal accomplishment $(\beta=0.433, \mathrm{p}<$ $0.0001)$ of $\mathrm{MBI}$ and conscientiousness $(\beta=0.233, \mathrm{p}=0.031)$ of NEO-FFI were significantly related to empathy (Table 5-2).

In multiple regression analysis for whole students, the model was statistically significant $(\mathrm{F}=18.415, \mathrm{p}<0.0001)$ and adjusted $\mathrm{R}$ square is 0.231 . Self-esteem $(\beta=0.176, p=0.004)$, conscientiousness $(\beta=0.201, \mathrm{p}=0.001)$ in the NEO-FFI, depersonalization and personal accomplishment $(\beta=-0.188, p=0.001, \beta=0.143$,

Table 5-1. Multiple linear regression analysis of empathy and related factors in medical students (male)

\begin{tabular}{lccccc}
\hline \multicolumn{5}{c}{ JSE-S-K } \\
\hline $\mathrm{R}^{2}$ & \multicolumn{5}{c}{0.249} \\
Adjusted R & 0.238 \\
p-value* & \multicolumn{5}{c}{$<0.0001$} \\
$\mathrm{~F}^{*}$ & & \multicolumn{5}{c}{21.247} \\
\hline Dependent variables & $\mathrm{B}$ & $\mathrm{SE}$ & $\beta$ & $\mathrm{P}$ & VIF \\
\hline (Constant) & 76.641 & 8.345 & & $<0.0001$ \\
R-SES & 0.695 & 0.197 & 0.248 & 0.001 & 1.260 \\
C & 0.469 & 0.149 & 0.214 & 0.002 & 1.175 \\
DP & -0.599 & 0.179 & -0.221 & 0.001 & 1.122 \\
\hline
\end{tabular}

*ANOVA. JSE-S-K: Jefferson Scale of Empathy, Student version, Korean edition, R-SES: Rosenberg Self-Esteem Scale, C: conscientiousness, DP: depersonalization

Table 5-2. Multiple linear regression analysis of empathy and related factors in medical students (female)

\begin{tabular}{lrrrcc}
\hline \multicolumn{5}{c}{ JSE-S-K } \\
\hline $\mathrm{R}^{2}$ & \multicolumn{5}{c}{0.317} \\
Adjusted R $^{2}$ & \multicolumn{5}{c}{0.298} \\
p-value* $^{*}<0.0001$ & & \\
$\mathrm{~F}^{*}$ & & \multicolumn{5}{c}{16.462} \\
Dependent variables & $\mathrm{B}$ & $\mathrm{SE}$ & $\beta$ & $\mathrm{P}$ & $\mathrm{VIF}$ \\
\hline (Constant) & 57.185 & 10.326 & & $<0.0001$ & \\
PA & 0.906 & 0.221 & 0.433 & $<0.0001$ & 1.161 \\
C & 0.552 & 0.251 & 0.233 & 0.031 & 1.161 \\
\hline
\end{tabular}

*ANOVA. JSE-S-K: Jefferson Scale of Empathy, Student version, Korean edition, C: conscientiousness, PA: personal accomplishment $\mathrm{p}=0.017)$ in the MBI and $\operatorname{sex}(\beta=0.117, \mathrm{p}=0.029)$ were significantly associated with empathy (Table 6).

\section{DISCUSSION}

The present study multi-laterally analyzed factors influencing the empathy of medical students, and identified that conscientiousness, depersonalization, personal accomplishment and self-esteem had significant effects on empathy. Unlike previous studies, this study found that openness and agreeableness in the subscales of the NEO-FFI were not associated with empathy. ${ }^{18,19}$ In addition, our results indicate that only conscientiousness was influential. It has been shown that conscientious doctors have better clinical ability ${ }^{17}$ and that clinical ability and empathy are positively correlated..$^{40}$ Moreover, since conscientious people tend to actively resolve conflicts with others and less likely to cause trouble for others ${ }^{41}$ they may be perceived as being more empathetic. ${ }^{42}$

In this study, self-esteem and depersonalization affect empathy more in male students whereas personal accomplishment affects empathy more in female students. Male, in comparison to female, is prone to being depersonalized because of different coping strategies..$^{30,43,44}$ Since students with high depersonalization are likely to feel cynicism and emotional distance, it could be speculated that these students would have trouble feeling empathic towards patients. ${ }^{43}$ In contrast, female medical students tend to be more keen on their academic performance than male students. ${ }^{45}$ This may explain the finding from this study that empathy of female students is affected by personal accomplishment.

People with high self-esteem are less likely to be caught up

Table 6. Multiple linear regression analysis of empathy and related factors in medical student

\begin{tabular}{lccccc}
\hline \multicolumn{5}{c}{ JSE-S-K } \\
\hline $\mathrm{R}^{2}$ & \multicolumn{5}{c}{0.259} \\
Adjusted $^{\mathrm{R} 2}$ & \multicolumn{5}{c}{0.245} \\
p-value* $^{*}$ & \multicolumn{5}{c}{$<0.0001$} \\
$\mathrm{~F}^{*}$ & & & \\
\hline Dependent variables & $\mathrm{B}$ & $\mathrm{SE}$ & $\beta$ & $\mathrm{P}$ & $\mathrm{VIF}$ \\
\hline (Constant) & 67.499 & 7.998 & & $<0.001$ & \\
R-SES & 0.481 & 0.166 & 0.176 & 0.004 & 1.327 \\
C & 0.452 & 0.133 & 0.201 & 0.001 & 1.256 \\
DP & -0.521 & 0.158 & -0.188 & 0.001 & 1.158 \\
PA & 0.328 & 0.136 & 0.143 & 0.017 & 1.261 \\
SEX & 3.679 & 1.674 & 0.117 & 0.029 & 1.015 \\
\hline
\end{tabular}

*ANOVA. JSE-S-K: Jefferson Scale of Empathy, Student version, Korean edition, R-SES: Rosenberg Self-Esteem Scale, C: conscientiousness, PA: personal accomplishment, DP: depersonalization, CD-RS: Conner-Davidson Resilience Scale 
in their own psychological burdens, ${ }^{22}$ may pay more attention, and provide help to others. Therefore, self-esteem could have a positive effect on empathy. ${ }^{20,22}$ In our study, self-esteem is related to empathy only in male students. Female tend to be more interdependent than male and this tendency is relatively stable regardless of self-esteem in comparison to male. ${ }^{46} \mathrm{Fu}$ ture studies to further explore self-esteem and empathy is warranted, as there are insufficient data on the influence of selfesteem on empathy among medical students. The findings from this study may provide a basis for supporting the claim that self-esteem positively affects empathy. Furthermore, selfesteem is a result of the accumulation of successful achievements in relationship with parents and developmental tasks, from childhood to adulthood, and it is not gained within a short period of time. Therefore, in order to verify more sophisticated causal relationships, a well-designed longitudinal study is needed.

In the present study, it was difficult to identify a consistent difference when empathy of students in one academic year was compared. However, female students were found to have greater empathy than male students. ${ }^{43,47}$ This observation may be attributed to the fact that females tend to understand the experiences and emotions of patients better than males. ${ }^{2,40}$

According to our regression analysis, gender difference $(\beta=$ 0.117 ) is less influential than other psychological factors such as conscientiousness, depersonalization, self-esteem and personal accomplishment $(\beta=0.201,-0.188,0.176,0.143)$ to empathy. This is an encouraging result to the educators of medical college that empathy could be improved by enhancing selfesteem, conscientiousness, personal accomplishment and relieving depersonalization.

It has been controversial whether empathy is the 'traits', highly stable and hard to change, or 'state', relatively unstable personality attributes, easy to change such as moods. ${ }^{7}$ The conclusion on whether empathy is the trait or the state was not drawn in this study. But our finding added a part of evidence on Hojat's opinion that it can be improved by therapeutic interventions. ${ }^{7}$ Although empathy may not be enhanced during short period, nurturing empathetic clinician is still important and the curriculum of medical school have to be highlighted on this issue.

In terms of enhancing empathy, it has been reported that 2.5 hours of meditation every week, for 8 weeks, resulted in the improvement of scores for depersonalization, emotional exhaustion, and personal accomplishment. ${ }^{48}$ This suggests that medical students may be able to recover from burnout using mindfulness. Moreover, self-esteem, conscientiousness and empathy also improved with mindfulness among other college students, in addition to medical students. ${ }^{48-50}$ Therefore, interventional or educational approaches, such as mindfulnessbased techniques, may be helpful for improving psychosocial correlates of empathy in medical students.

There are some limitations in the present study. First, it was conducted in a single medical college; therefore, the results may not be generalizable or applicable to all medical students in South Korea. However, since the response rate was very high (95\%), the results are representative of the Seonam University College of Medicine. Second, due to a cross-sectional study design, there is a need to conduct a longitudinal or cohort study to prove the causal relationships found in this study. Third, the applied tool was a series of self-reporting questionnaires, with no cross checks. In future studies, we will consider supplementing self-reporting questionnaires with (semi)structured tools.

This study is the first to comprehensively investigate multiple psychosocial variables affecting empathy in a single medical student group of Korea. From the present findings, it can be concluded that conscientiousness, depersonalization, and self-esteem have a significant impact on empathy. These factors and an interventional approach must be considered when educating medical students to become empathetic doctors.

\section{Acknowledgments}

We thank all the students of Seonam University, College of Medicine, for their participation.

This work was supported by the Research Fund (grant No. 1601-02-01) of Myongji Hospital.

\section{Conflicts of Interest}

The authors have no potential conflicts of interest to disclose.

\section{Author Contributions}

Conceptualization: Minha Hong, Sang Min Lee, Won Woo Suh. Data curation: Won Woo Suh, Hyun Soo Kim, Hoo Rim Song. Formal analysis: Ji Yeon Yoo, Sung Hyun Cho. Investigation: Won Woo Suh, Woo Jung Kim, Minha Hong, Sang Min Lee. Writing_original draft: Won Woo Suh, Ji Yeon Yoo, Sung Hyun Cho, Hoo Rim Song, Woo Jung Kim. Writing_review \& editing: Hyun Soo Kim, Minha Hong, Sang Min Lee. All authors read and approved the final version of the manuscript.

\section{ORCID iDs}

Minha Hong

Sang Min Lee

Won Woo Suh

https://orcid.org/0000-0003-4924-1107 https://orcid.org/0000-0002-7834-8272 https://orcid.org/0000-0001-6405-5439

\section{REFERENCES}

1. Sadock BJ, Sadock VA, Ruiz P. Kaplan \& Sadock’s Synopsis of Psychiatry. Behavioral Sciences/Clinical Psychiatry. Philadelphia: Wolters Kluwer Health; 2015.

2. Hojat M, Gonnella JS, Nasca TJ, Mangione S, Vergare M, Magee M. Physician empathy: definition, components, measurement, and relationship to gender and specialty. Am J Psychiatry 2002;159:1563-1569.

3. Glaser KM, Markham FW, Adler HM, McManus PR, Hojat M. Relationships between scores on the Jefferson Scale of physician empathy, patient perceptions of physician empathy, and humanistic approaches to patient care: a validity study. Med Sci Monit 2007;13:291-294.

4. Learning objectives for medical student education--guidelines for medical schools: report I of the Medical School Objectives Project. Acad 
Med 1999;74:13-18.

5. Jeon WT, Kim AY. Present and future of Korean medical education the role of Yonsei University`s medical education. Yonsei J Med History 2017;20:51-68.

6. Cole DA, Martin NC, Steiger JH. Empirical and conceptual problems with longitudinal trait-state models: introducing a trait-state-occasion model. Psychol Methods 2005;10:3-20.

7. Hojat M. Empathy in Health Professions Education and Patient Care. Philadelphia: Springer;2016.

8. Hojat M, Mangione S, Nasca TJ, Cohen MJM, Gonnella JS, Erdmann JB, et al. The Jefferson Scale Of Physician Empathy: development and preliminary psychometric data. Educ Psychol Meas 2001;61:349-365.

9. Kataoka HU, Koide N, Ochi K, Hojat M, Gonnella JS. Measurement of empathy among Japanese medical students: psychometrics and score differences by gender and level of medical education. Acad Med 2009; 84:1192-1197.

10. Lee BK, Bahn GH, Lee WH, Park JH, Yoon TY, Baek SB. The relationship between empathy and medical education system, grades, and personality in medical college students and medical school students. Korean J Med Educ 2009;21:117-124.

11. Walocha ET, Tomaszewski KA, Ruzyczka E, Walocha J. Empathy and burnout among physicians of different specialities. Folia Med Cracov 2013;53:35-42.

12. Shanafelt TD, Sloan JA, Habermann TM. The well-being of physicians. Am J Med 2003;114:513-519.

13. Brazeau CM, Schroeder R, Rovi S, Boyd L. Relationships between medical student burnout, empathy, and professionalism climate. Acad Med 2010;85:S33-S36.

14. Hojat M, Vergare M, Isenberg G, Cohen M, Spandorfer J. Underlying construct of empathy, optimism, and burnout in medical students. Int J Med Educ 2015;6:12-16.

15. Epstein RM, Krasner MS. Physician Resilience: what it means, why it mattes and how to promote it. Acad Med 2013;88:301-303.

16. Olson K, Kemper KJ, Mahan JD. What factors promote resilience and protect against burnout in first year pediatric and medicine pediatric residents? J Evid Based Complementary Altern Med 2015;20:192-198.

17. Hojat M, Erdmann JB, Gonnella JS. Personality assessments and outcomes in medical education and the practice of medicine: AMEE Guide No. 79. Med Teach 2013;35:e1267-e1301.

18. Costa P, Alves R, Neto I, Marvao P, Portela M, Costa MJ. Associations between medical student empathy and personality: a multi-institutional study. PLoS One 2014; 9: e89254.

19. Magalhaes E, Costa P, Costa MJ. Empathy of medical students and personality: evidence from the Five-Factor Model. Med Teach 2012;34:807-812.

20. Cone VP. Self-Esteem's Relations to Empathy and Parenting. PSYCT 2016;9:184-196.

21. Passanisi A, Gensabella A, Pirrone C. Parental bonding, self-esteem and theory of mind among locals and immigrants. Procedia Soc Behav Sci 2015;47:1702-1706.

22. Stotland E, Dunn R. Empathy, self-esteem and birth order. J Abnorm Soc Psychol 1963;66:532-540.

23. Eisenberg N. Empathy-Related Emotional Responses, Altruism and Their Socialization. In: Davidson R, Harrington A, Editors. Visions of Compassion: Western Scientists and Tibethan Buddhists Examine Human Nature. Oxford: Oxford University Press, 2002, p.131-164.

24. Eisenberg N, Eggum ND. Empathic Responding: Sympathy and Personal Distress. In: Decety J, Ickes W, Editors. The Social Neuroscience of Empathy. Cambridge, MA: The MIT press, 2009, p.71-83.

25. Laible DJ, Carlo G, Roesch SC. Pathways to self-esteem in late adolescence: The role of parent and peer attachment, empathy, and social behavior. J Adolesc 2004;27:703-716.

26. Hong M, Lee WH, Park JH, Yoon TY, Moon DS, Lee SM, et al. Changes of empathy in medical college and medical school students: 1-year follow up study. BMC Med Educ 2012; 12: 122.

27. Park C, Lee YJ, Hong M, Jung CH, Synn Y, Kwack YS, et al. A Multicenter study investigating empathy and burnout characteristics in med- ical residents with various specialties. J Korean Med Sci 2016;31:590-597.

28. Hong M, Bahn GH, Lee WH, Moon SJ. Empathy in Korean psychiatric residents. Asia Pac Psychiatry 2011;3:83-90.

29. Roh MS, Hahm BJ, Lee DH, Suh DH. Evaluation of empathy among Korean medical students: a cross-sectional study using the Korean Version of the Jefferson Scale of Physician Empathy. Teach Learn Med 2010; 22:167-171.

30. Maslach C, Schaufeli WB, Leiter MP. Job burnout. Annu Rev Psycho 2001;52:397-422.

31. Kang JH, Kim CW. Evaluating applicability of Maslach burnout Inventory among university hospitals nurses. Korean J Adult Nurs 2012;24:31-37.

32. Connor KM, Davidson JR. Development of a new resilience scale: the Connor-Davidson Resilience Scale (CD-RISC). Depress Anxiety 2003; 18:76-82.

33. Baek HS, Lee KU, Joo EJ, Lee MY, Choi KS. Reliability and validity of the korean version of the connor-davidson resilience scale. Psychiatry Investig 2010;7:109-115.

34. Rosenberg M. Society and the Adolescnt Self Image. Princeton, NJ: Princeton University Press; 1965.

35. Lee YJ. Relations of Stress, Social Support, and Self-Esteem to Depression and Anxiety. Seoul: Graduate School of Education, Seoul Women University; 1994.

36. Costa PT, McCrae RR. Revised NEO Personality Inventory (NEO PIR) and NEO Five-Factor Inventory (NEO-FFI): Professional Manual. Odessa: Psychological Assessment Resources; 1992.

37. Lievens F, Coetsier P, De Fruyt F, De Maeseneer J. Medical students' personality characteristics and academic performance: a five-factor model perspective. Med Educ 2002; 36: 1050-1056.

38. Ahn CK, Chae JH. Standardization of the Korean version of the revised NEO Personality Inventory. Korean J Counsel and Psychother 1997;9:443473.

39. Cohen J. Statistical Power Analysis for the Behavioral Science. Lawrence Erlbaum Associates; 1988.

40. Hojat M, Gonnella JS, Mangione S, Nasca TJ, Veloski JJ, Erdmann JB, et al. Empathy in medical students as related to academic performance, clinical competence and gender. Med Educ 2002;36:522-527.

41. Roberts BW, Jackson JJ, Fayard JV, Edmonds G, Meints J. Conscientiousness. In: Leary MR,Hoyle RH, Editors. Handbook of Individual Differences in Social Behavior. New York: Guilford, 2009, p. 369-381.

42. Song Y, Shi M. Associations between empathy and big five personality traits among chinese undergraduate medical students. PLoS One 2017; 12:e0171665.

43. Paro HB, Silveira PS, Perotta B, Gannam S, Enns SC, Giaxa RR, et al. Empathy among medical students: is there a relation with quality of life and burnout? PLoS One 2014;9:e94133.

44. Purvanova RK, Muros JP. Gender differences in burmout: a meta-analysis. J Vocat Behav 2010;77:168-185.

45. Chandavarkar U, Azzam A, Mathews CA. Anxiety symptoms and perceived performance in medical students. Depress Anxiety 2007;24:103111.

46. Josephs RA, Markus HR, Tafarodi RW. Gender and self-esteem. J Pers Soc Psychol 1992;63:391-402.

47. Hojat M, Gonnella JS, Nasca TJ, Mangione S, Veloksi JJ, Magee M. The Jefferson Scale of Physician Empathy: further psychometric data and differences by gender and specialty at item level. Acad Med 2002;77 (10 Suppl):S58-S60.

48. Krasner MS, Epstein RM, Beckman H, Suchman AL, Chapman B, Mooney CJ, et al. Association of an educational program in mindful communication with burnout, empathy, and attitudes among primary care physicians. JAMA 2009;302:1284-1293.

49. Shapiro SL, Schwartz GE, Bonner G. Effects of mindfulness-based stress reduction on medical and premedical students. J Behav Med 1998;21: 581-599.

50. Michael K, Rasmussen AM. The direct and indirect benefits of dispositional mindfulness on self-esteem and social anxiety. Anxiety Stress Coping 2010;24:227-233. 